\title{
TIPOLOGIAS BIOFÍLICAS NA PERCEPÇÃO SOBRE A CAÇA EM UMA COMUNIDADE RURAL DO RECÔNCAVO DA BAHIA: SUBSÍDIOS À EDUCAÇÃO AMBIENTAL PARA CONSERVAÇÃO DA BIODIVERSIDADE
}

\author{
Divaney Mamédio dos Santos ${ }^{1}$ \\ Marcos da Cunha Teixeira ${ }^{2}$ \\ Jesus Manuel Delgado Mendez ${ }^{3}$ \\ Adevan da Silva Pugas ${ }^{4}$
}

Resumo: Investigamos as tipologias biofílicas em uma comunidade rural da Região do Recôncavo da Bahia. Os resultados permitem afirmar que, embora ainda presente na comunidade, a caça não é uma atividade crucial para a sobrevivência dos moradores. Registramos a presença de 4 das 9 tipologias biofílicas propostas na literatura, com destaque para o humanismo. Enxergamos a comunidade como um campo fértil para os trabalhos de educação ambiental transformadora tendo as tipologias biofílicas registradas neste estudo como ponto de partida, pois, qualquer tentativa nesse sentido, deverá respeitar os conhecimentos e valores culturais construídos pela comunidade.

Palavras-chave: Biofilia; Conservação; Cultura; Fauna; Meio ambiente.

\footnotetext{
1 Doutorando em Ciencias Agrícolas y Medioambientales da Universidade de Santiago de Compostela, Espanha. Bolsista Egresso do Programa de Educação Tutorial Conexões de Saberes Socioambientais. Email: divaneymds@yahoo.com.br

2 Professor Adjunto da Universidade Federal do Espírito Santo - Campus São Mateus, Coordenador do Núcleo de Práticas Pedagógicas em Biologia e Educação Ambiental, Tutor egresso do Programa de Educação Tutorial Conexões de Saberes Socioambientais. E-mail: marcosteixeiraufes@gmail.com.

${ }^{3}$ Professor da Universidade Federal do Recôncavo da Bahia, Brasil. Tutor do Programa de Educação Tutorial Conexões de Saberes Socioambientais. E-mail: jesusd@uol.com.br.

${ }^{4}$ Graduando do Curso Tecnólogo em Agroecologia da Universidade Federal do Recôncavo da Bahia, Bolsista do Programa de Educação Tutorial Conexões de Saberes Socioambientais. E-mail: vanpugas1@hotmail.com.
} 


\section{Introdução}

Philippe Pomier Layrargues, em sua apresentação da obra "Identidades da educação ambiental brasileira" (BRASIL, 2004), nos alerta para a impossibilidade de se traduzir ou reduzir as múltiplas orientações numa única educação ambiental. Esse aspecto demonstra que a educação ambiental ainda é um campo do conhecimento em construção e, como tal, bastante fértil à construção de propostas que contribuam para repensarmos nossa relação com o mundo. Entre os campos do conhecimento que procuram compreender os aspectos que definem as formas de nos relacionarmos com a natureza a Psicologia ambiental vem dando significativa contribuição à Educação ambiental a partir dos estudos sobre Biofilia (do grego bios = vida + philia $=$ amor, afeição - significa literalmente "amor pela vida").

A hipótese da Biofilia proposta pelo biólogo Americano Eduard $\mathrm{O}$. Wilson (1984, p. 39) defende a ideia da existência de uma necessidade intrínseca do ser humano manter algum vínculo com a natureza. Wilson sugere que essa ligação emocional deve estar nos nossos genes, ou seja, tornou-se hereditária, provavelmente porque $99 \%$ da história da humanidade não se desenvolveram nas cidades, mas em convivência íntima com a natureza (WILSON, 2002, p.153). A partir dessa hipótese, o autor propôs a existência de três graus de altruísmos, os quais explicariam a percepção e as ações dos indivíduos sobre o meio:

- antropocentrismo: percepção de que apenas o que tem impacto para o homem é importante;

- empatocentrismo: percepção de que alguns direitos devem ser compartilhados com alguns animais que causam empatia aos humanos.

- biocentrismo: guarda a ideia de que todos os organismos possuem os mesmos direitos.

A hipótese da Biofilia reflete o interesse do movimento ambientalista a partir da segunda metade do século $X X$, que rejeita as soluções tecnocráticas para crise ecológica (KRMÁROVÁ, 2009). A partir da hipótese de Wilson, pesquisadores dos diversos campos tem se dedicado a investigar padrões sobre o efeito da relação com a natureza sobre a saúde e bem-estar de populações nas áreas urbanas (LEE et al., 2011; PARK et al., 2011; RYAN et al., 2014; REVEL; ANDA, 2014).

Oliveira e Corona (2008, p. 60-68) explicam que as tipologias biofílicas expressam os valores individuais ou coletivos que orientam a relação dos seres humanos com o mundo natural e que poderiam servir como elementos na compreensão de diferentes concepções e propostas de intervenção sobre o ambiente natural. Assim, a explicitação das tipologias contribui para compreender as formas de construção da percepção das pessoas sobre 0 Revbea, São Paulo, V.10, N²: 25-35, 2015. 
ambiente. Esse tipo de trabalho ganha importância para que medidas como a de projetos para Educação ambiental tenham eficácia uma vez que a percepção ocorre de formas variadas. A Educação ambiental, tendo conhecimento dos valores e ações dos sujeitos frente ao meio ambiente, será capaz de elaborar propostas que atinjam grande parte da sociedade e provoque mudanças mais efetivas capazes de contribuir para a sustentabilidade socioambiental (OLIVEIRA; CORONA, 2008, p. 70).

Apoiando-nos na hipótese da Biofilia, é possível que as percepções das comunidades que mantém maior vínculo cotidiano com a natureza sejam diferentes dos preceitos e acordos construídos com base na realidade das sociedades urbanas, o que pode gerar sérios conflitos. Por exemplo, a caça, atividade que sempre esteve presente na cultura dos povos do campo, ainda permanece no cotidiano de muitas comunidades rurais, gerando conflitos socioambientais devido às proibições legais e às políticas públicas em favor da conservação da biodiversidade. Diante das pressões dessas políticas sobre e das penalidades previstas na legislação para aqueles que praticarem a caça, a pergunta que se abre é: quais mudanças têm ocorrido na percepção dos moradores das comunidades do campo sobre sua relação com os animais silvestres? Guiado por essa questão e tomando a hipótese da Biofilia como referencial, o presente estudo objetivou caracterizar a percepção ambiental dos moradores de uma comunidade rural localizada na Região do Recôncavo da Bahia sobre a prática da caça.

O presente trabalho é parte do Programa de Estudo Socioambientais da Comunidade Rural de Laranjeiras, Muritiba-BA desenvolvido pelo Programa de Educação Tutorial Conexões de Saberes Socioambientais ("PET Roça"). A partir dos resultados, espera-se contribuir com a construção de soluções para questões importantes apontadas pela comunidade como desafios a serem superados pelo coletivo local.

\section{Material e Método}

\section{Local de estudo}

O município de Muritiba esta inserido na região do Recôncavo da Bahia $\left(12^{\circ} 38^{\prime} 13^{\prime \prime} \mathrm{S}\right.$ e $39^{\circ} 5^{\prime} 45^{\prime \prime} \mathrm{W}$ ) e possui 27.212 habitantes (IBGE, 2010), que se dedicam basicamente da agricultura, da pecuária e da silvicultura. $O$ estudo foi desenvolvido na Comunidade Rural de Laranjeiras formada por 110 famílias, sendo que cada uma é composta por mais de quatro residentes. A principal característica da comunidade é a presença de grande extensão de terra ocupada pela cultura de tabaco, mantida por uma empresa multinacional. Mesmo assim, ainda podem ser observados pequenos fragmentos da Mata Atlântica e alguns mananciais com benefícios compartilhados pelos moradores. 


\section{Sujeitos da pesquisa}

Foram entrevistados 32 moradores cujas idades variavam de 10 a 81 anos dos quais, 15 eram mulheres e 17 homens. As identidades dos entrevistados foram mantidas em sigilo e os mesmos foram identificados com a letra "M", inicial de morador, seguida do número sequencial em que ocorreram as entrevistas.

\section{Coleta e análise dos dados}

Para avaliar a percepção dos moradores em relação à caça, realizouse um levantamento através de aplicação de questionário semiestruturado além de entrevistas abertas e observações de campo nos meses de agosto e setembro de 2012. Os da $\neg$ dos qualitativos, obtidos a partir das questões abertas, foram analisados por meio de análise de conteúdo categorial temática (BARDIN, 1977, p. 38). Essa abordagem se configura pela identificação das categorias que surgem no conjunto das respostas dos entrevistados às questões subjetivas. Os dados coletados foram compilados, apreciados e sintetizados e em seguida foi realizada a identificação das tipologias biofílicas propostas por Kellert (1993) citados por Oliveira e Corona (2008), a saber: utilitarista, negativista, moralista, simbólica, estética, dominionística, naturalista, humanista, ecológico-científica.

\section{Resultados e Discussão}

Os entrevistados apresentavam idades variando de 10 a 81 anos dos quais, 15 mulheres e 17 homens. Esses sujeitos estão inseridos em um universo da comunidade no quais $27 \%$ não são alfabetizados ou se consideram semialfabetizado, $41 \%$ possuem ensino fundamental incompleto, $27 \%$ possuem ensino médio completo ou não e $5 \%$ com superior completo ou não. $12 \%$ possuem água encanado-tratada e $88 \%$ utilizam água de poço artesiano. Em relação ao lixo, $72 \%$ queimam e $28 \%$ enterram. No que diz respeito ao acesso de programa social, $94 \%$ dizem possuir bolsa família e $6 \%$ auxílio defeso. A agricultura foi declarada por $62 \%$ dos entrevistados como principal atividade e a produção está assim distribuída: $61 \%$ são destinadas à subsistência e $35 \%$ para venda no comércio do município. Tomando o salário mínimo como base, a renda familiar ficou assim caracterizada: meio salário $(63 \%)$ um salário mínimo $(23 \%)$ e um a dois salários (14\%). As despesas que mais comprometem a renda são: alimentação (33\%), gás (22\%), saúde (19\%), energia (16\%), educação (5\%), dentre outros. Os principais meios de comunicação e de informação utilizados pelos moradores da comunidade é a televisão (50\%) seguida do rádio (44\%). Quanto à organização social, cita-se a existência da Associação de Produtores e Associação de Mulheres.

Os dados expressados acima fazem parte do perfil socioeconômico da Comunidade Rural de Laranjeiras, traçado através de uma pesquisa realizada pelo Programa de Educação Tutorial Conexões de Saberes Socioambientais, da Universidade Federal do Recôncavo da Bahia. 


\section{Aspectos biofílicos da caça na Comunidade Rural de Laranjeiras}

As tabelas I, II e III reúnem os principais resultados obtidos para as tipologias biofílicas, as percepções quanto à legalidade da prática de caça e quanto aos motivos que justificam a caça, respectivamente.

Quando questionamos se o morador "já soube ou presenciou algum ato de caça em sua localidade", 24 disseram que sim e sete afirmaram que não. Além disso, 25 entrevistados atestaram que a caça é uma prática antiga na localidade, o que revela que a comunidade ainda mantém uma forte relação com os animais silvestres. Quando questionamos ao entrevistado se ele "caça ou já caçou em algum momento da vida", sete declararam que nunca caçaram e 15 afirmaram que caçavam mais de quatro vezes no mês. O restante, que afirmou praticar a caça, em sua maioria destina um turno de seu dia para praticar a atividade, sendo que estes ficam assim representados: $49 \%$ turno da manhã e $29 \%$ durante o dia todo. Pode ser verificado que há um maior envolvimento dos homens nessa atividade, confirmando a tradição rural na qual a figura masculina é a responsável pela manutenção da família.

Sobre "quais animais são caçados", a ordem de preferência dos moradores mostrou-se assim: pássaros (18), coelho (12), tatu (8) e teiú (6), seguidos dos demais, conforme a tabela I. Quando questionados sobre "qual animal que não é caçado de jeito nenhum?" 50\% não responderam à questão, deixando subentendido que qualquer animal estaria passivo de ser caçado em algum momento. A afirmação de que "só não caçamos aqueles que não têm mais na mata" (M7) reforçam essa hipótese.

Conforme ficou evidenciado nos discursos dos entrevistados, a caça é uma prática antiga na comunidade e ainda aparece de forma significativa no cotidiano dos moradores, mesmo que de forma indireta. Por isso, a ideia de indignar-se com o sofrimento dos animais não seria um aspecto esperado nos resultados da pesquisa. No entanto, a afirmação de que "não pode criar os animais presos, pois os mesmos devem viver em liberdade" (M5) revela a presença de algum grau de empatocentrismo, proposto por Wilson (1984), uma vez que revela preocupação com os direitos das espécies animais. Mas, esse não é o principal elemento motivador para que os moradores se posicionem contra a caça (Tabela 1), pois a maior preocupação tem fundo emocional (52\%). Santos e Machado (2006, p. 312-314) propõem que esta perspectiva está ligada à convicção de que existe na natureza um significado espiritual, de ordem e de harmonia, que tende a preservar a integridade, a estabilidade e a beleza do ambiente natural. Por isso, o uso constante do termo "bichinhos" para se referir aos animais silvestres, explicita a ideia de cuidado e proteção, colocando-os como seres indefesos diante da maldade do homem. Esse sentimentalismo ficou bastante explicito em discursos como o que segue: "Porque os bichinhos saem procurando comida e as pessoas vão e mata" (M 10). Discursos como esses reafirmam a análise de Santos e Machado (2006, p. 318), que, ao discutirem os valores presentes na tipologia humanista, afirmam que "a experiência moralista da natureza refere-se aos sentimentos fortes de afinidade, responsabilidade ética e, até mesmo, reverência e respeito para com

revista brasileira educação ambiental 
o mundo natural'. Kellert (1993), citado por Santos e Machado (2006), assevera que a experiência humanista da natureza, de acordo com a hipótese biofílica, é responsável por uma forte tendência em cuidar de seus elementos individuais. Notamos, nesse caso, a existência do terceiro sentimento biofílico proposto por Wilson: o biocentrismo (p.153).

Tabela 1: Tipologias biofílicas registradas a partir da percepção sobre a caça entre os moradores da comunidade rural de Laranjeiras, Muritiba-BA.

\begin{tabular}{|c|c|c|}
\hline $\begin{array}{l}\text { Tipologias } \\
\text { biofílicas }\end{array}$ & Alguns depoimentos & $\begin{array}{c}\text { Moradores } \\
\text { no (\%) }\end{array}$ \\
\hline $\begin{array}{c}\text { Humanism } \\
0\end{array}$ & $\begin{array}{l}\text { "Porque os bichinhos saem procurando comida e as pessoas vão e } \\
\text { matam". } \\
\text { "Para que matar os bichinhos, deixa lá!" } \\
\text { "Não pode criar os animais presos, pois, os mesmos devem viver } \\
\text { em liberdade". } \\
\text { "Não pode andar matando os bichinhos, tem que ter consciência } \\
\text { das coisas". } \\
\text { "Sou contra a quem mata os bichos, caçar não é para se matar". }\end{array}$ & $17(55)$ \\
\hline Moralismo & $\begin{array}{l}\text { "É um crime matar os animais para comer". } \\
\text { "É um crime apreender animais". } \\
\text { "Não pode (em tom de proibição) caçar, matar os bichos". }\end{array}$ & $9(29)$ \\
\hline $\begin{array}{c}\text { Utilitarism } \\
0\end{array}$ & $\begin{array}{l}\text { "Às vezes a caça é desnecessária, pois, praticam este ato para se } \\
\text { divertir". } \\
\text { "Hoje em dia não é mais necessário caçar". } \\
\text { "Varias pessoas caçam para se alimentar e outras não". } \\
\text { "Não adianta nada por que as pessoas não vivem daquilo". } \\
\text { "Sou a favor. É uma diversão". }\end{array}$ & $4(13)$ \\
\hline Estética & "A natureza é coisa linda que Deus fez. Tem de ser preservada". & $1(3)$ \\
\hline
\end{tabular}
Fonte: Autoria própria.

Na direção oposta ao biocentrismo, os valores de cuidado, que aparece com a tipologia humanística, também foram utilizados para justificarem a caça quando alguns entrevistados afirmam, por exemplo, que "pegar e dar para uma pessoa que cuida não é crime" (M26). Percepções desse tipo confirmam o que Zago (2008) constatou de que as pessoas acreditam estar protegendo esses animais. O autor alerta ainda (p. 10) que "grande parte das pessoas que possuem animais da fauna silvestre os adquire ilegalmente, não tendo consciência de estar incorrendo em crime ambiental'. No entanto, esse aspecto não aparece de forma significativa na comunidade estudada. Nesse contexto, cita-se o registro da tipologia moralismo, pois alguns moradores (29\%) se apegarem ao aspecto proibitivo oficial. Santos e Machado (2006, p. 318) reiteram que,

a experiência moralista da natureza refere-se aos sentimentos fortes de afinidade, responsabilidade ética e, até mesmo, reverência e respeito para com o mundo natural. Esta perspectiva está ligada à convicção de que existe na natureza um significado espiritual, de ordem e de harmonia, que tende a preservar a integridade, a estabilidade e a beleza do ambiente natural. 
O aparecimento da tendência moralista entre $29 \%$ dos entrevistados pode ser um efeito da ampla divulgação das políticas públicas de conservação da biodiversidade, em especial da fauna. Esse resultado mostra que há na comunidade um forte desejo de que as ações humanas para com o ambiente sejam permeadas pela ética.

Quando os moradores admitem que "quando caça por necessidade, para comer, não é crime" (M21), mas, que "se caça animal que está acabando não pode" (M14), nota-se uma clara articulação dos valores antigos praticados na comunidade com aqueles veiculados ou mesmo impostos pelas políticas públicas de proteção aos animais silvestres. Da mesma forma, quando admitem que "pode se caçar para comer" (M9). Nesse desconhecimento do aspecto legal (Tabela 2) é possível que a percepção sobre a caça seja guiada por um componente ético cultural que ainda não foi confrontado com as prerrogativas da lei, pois alguns afirmaram que "Hoje o pessoal acha que é crime. Quando caça por necessidade, para comer, não é crime" (M11). Esses resultados evidenciam o forte vínculo que a comunidade ainda mantém com a natureza e o quanto os elementos naturais estão presentes nos valores socialmente compartilhados. Dessa forma, confirma-se, aqui, que o primeiro sentimento biofílico proposto por Wilson, o antropocentrismo, está fortemente presente naquela comunidade rural.

Tabela 2: Percepções dos moradores da Comunidade rural de Laranjeiras, Muritiba-Ba sobre a legalidade da caça.

\begin{tabular}{|c|c|c|}
\hline Categoria & Alguns depoimentos colhidos & $\begin{array}{l}\text { Moradores } \\
\text { nํ (\%) }\end{array}$ \\
\hline $\begin{array}{l}\text { Toda } \\
\text { caça é } \\
\text { ilegal }\end{array}$ & $\begin{array}{l}\text { "É considerada um crime por que saem para matar } \\
\text { os bichinhos que não sabem de nada". } \\
\text { "Nunca ela vai ser considerada legal, pois, no } \\
\text { mundo inteiro é ilegal, mais para quem gosta de } \\
\text { caçar (os caçadores), para eles é legal". } \\
\text { "É ilegal porque mata e muitas vezes os animais } \\
\text { vão desaparecendo. A pesca alternativa (pesca e } \\
\text { solta), não é crime". } \\
\text { "É ilegal em toda circunstâncias, pois, levam os } \\
\text { passarinhos para casa e não tem cuidado". }\end{array}$ & $16(55)$ \\
\hline \multirow{3}{*}{$\begin{array}{l}\text { Quando } \\
\text { a caça } \\
\text { não é } \\
\text { ilegal }\end{array}$} & "Quando tem autorização do IBAMA". & $4(14)$ \\
\hline & $\begin{array}{l}\text { "Quando é para sobrevivência". } \\
\text { "Hoje o pessoal acha que é crime. Quando caça por } \\
\text { necessidade, para comer, não é crime”. }\end{array}$ & $4(14)$ \\
\hline & $\begin{array}{l}\text { "Pegar e dá a uma pessoa que cuida não é crime, } \\
\text { por que não matou". } \\
\text { "Quando os animais estão dando prejuízos, não é". } \\
\text { "Criava galinhas e a raposa vinha pegar na porta, } \\
\text { então reuni os vizinhos para matar a raposa". }\end{array}$ & $3(10)$ \\
\hline Outro & $\begin{array}{l}\text { "Quando tem prisão". } \\
\text { - Quando não pega para prender. }\end{array}$ & $2(7)$ \\
\hline
\end{tabular}

Fonte: Autoria própria. 
Conforme se pode observar na Tabela 2, o grupo que afirma que a caça nunca será legal (55\%) confirma o resultado de $53 \%$ para o grupo representativo da categoria do discurso humanista. Notamos coerência ainda com os resultados sobre os motivos para a prática da caça quando $56 \%$ dos respondentes afirmaram que a mesma é praticada por diversão.

Chama a atenção o grupo que admite algumas possibilidades em que a caça é legal, com destaque para o grupo que fez referência a autorização do IBAMA. No entanto, além da ideia de que caçar para comer não é crime, há ainda uma concepção de que não há ilegalidade no abate de animais silvestres quando estes geram prejuízos: "Criava galinhas e a raposa vinha pegar na porta, então reuni os vizinhos para matar a raposa" (M19).

Quando questionados sobre o que Ihes motivavam a praticar a caça, a maioria dos entrevistados apontou mais de uma razão condicionante a este ato (Tabela 3). Entre todas as respostas referentes a tal motivação, a diversão é a razão principal apontada por $56 \%$ dos entrevistados, seguido dos $28 \%$ das pessoas que afirmam ser a necessidade o fator impulsionador desta atividade. Outras razões foram relatadas, tais como: vício, contemplação.

Tabela 3: Percepções dos moradores de Laranjeiras, Muritiba-Ba sobre os motivos para prática da caça na comunidade.

\begin{tabular}{|c|c|c|}
\hline Categoria & Alguns depoimentos & $\begin{array}{c}\text { Moradores } \\
n^{0}=(\%)\end{array}$ \\
\hline Diversão & $\begin{array}{l}\text { "Os jovens de hoje caçam por diversão". } \\
\text { "Por diversão, comer com cachaça". } \\
\text { "Para distrair, para não ficar em casa. } \\
\text { "Para diversão, porque se tem comida em casa, para } \\
\text { que matar os animais para comer". }\end{array}$ & $22(56)$ \\
\hline Necessidade & $\begin{array}{l}\text { "As vezes para se alimentar". } \\
\text { "A maioria por diversão e outro por necessidade". } \\
\text { "Para comer, matar a fome". } \\
\text { "Antigamente era mais por necessidade, hoje é mais por } \\
\text { diversão". }\end{array}$ & $11(28)$ \\
\hline Vício/prazer/cultural & $\begin{array}{l}\text { "Só pelo vício de ver o cachorro correr e eles terem o } \\
\text { prazer de atirar para matar". } \\
\text { "Não é por necessidade é mais por prazer". }\end{array}$ & $3(8)$ \\
\hline Contemplação & $\begin{array}{l}\text { "Algumas pessoas caçam para criar". } \\
\text { "Para pegar os animais e levá-los para casa." } \\
\text { "Para prender, para observar seu canto." }\end{array}$ & $3(8)$ \\
\hline
\end{tabular}

Fonte: Autoria própria.

\section{Considerações finais}

As tipologias biofílicas bem como os discursos registrados no presente estudo permitiram identificar os três graus de altruísmos propostos por Wilson (2002, p. 153), os quais, segundo o autor, conduzem o indivíduo a respostas diferentes sobre o meio: 0 antropocentrismo, 0 empatocentrismo e 0 biocentrismo. Embora diversos esses sentimentos não são excludentes e Revbea, São Paulo, V.10, N²: 25-35, 2015. 
podem aparecer concomitantemente no cotidiano das pessoas (SANTOS e MACHADO, 2006). Dessa forma, o estudo confirma o forte vínculo da comunidade com a natureza, por meio da persistência das atividades de caça, mesmo que esta não represente uma atividade crucial de sobrevivência de nenhum morador da Comunidade. Portanto, a caça ainda persiste como um traço de uma comunidade que construiu sua cultura fortemente vinculada à natureza, ora exaltando-a, ora subjugando-a. Porém, os efeitos das políticas públicas de conservação da biodiversidade estão presentes, pois já aparece a ideia de que não se deve caçar e que essa atividade é ilegal. questões:

Diante dessas constatações, faz-se necessário responder as seguintes

- Os processos educacionais que visam a mudança de percepção das comunidades do campo sobre a conservação da biodiversidade têm respeitado os aspectos culturais historicamente construídos, ou tem agido sob os princípios da coerção?

- A existência de moradores cujas percepções e ações não guardam consonância com os aspectos legais do manejo de animais silvestres os colocam em uma condição marginal?

Longe da ideia de marginalidade, os discursos colhidos neste estudo estão respaldados pelos valores culturais e éticos há muito construídos, praticados e legitimados na comunidade. Possivelmente, esses indivíduos ainda não tiveram oportunidade de serem confrontados, em seus processos cognitivos, com os conhecimentos e valores individuais e sociais propostos e construídos pela educação ambiental. Se por um lado, a prática da caça persiste e busca respaldo na cultura da sobrevivência, por outro, é interessante registrar que, embora pouco frequente, alguns depoimentos deixam evidente que existe na comunidade o conhecimento, nem sempre presente na sociedade em geral, de que é possível a prática da caça com autorização dos órgãos oficiais do governo.

Os conhecimentos sobre a caça evidenciados entre os sujeitos pesquisados reafirmam a ideia de que no processo de construção das representações sociais, "o objeto entra em uma série de relacionamentos e de articulações com outros objetos que já se encontram nesse universo dos quais toma propriedades, ao mesmo tempo em que Ihes acrescenta as suas" (ALVES-MAZZOTI, 2008, p.24). Seguindo essa linha, enxergamos a comunidade de Laranjeiras como um campo fértil para os trabalhos de educação ambiental e consideramos necessária a introdução de novos elementos capazes de contribuir para uma revisão da relação do homem com a natureza. No entanto, qualquer tentativa nesse sentido deverá considerar como ponto de partida os conhecimentos e valores individuais e coletivos validados pela comunidade, "entendendo-os como determinações das contradições do seu tempo histórico, síntese de múltiplas determinações" (COSTA; LOUREIRO, 
2015, p.188). Nesse sentido, as percepções colhidas neste estudo representam o ponto de partida mais adequado.

Os resultados obtidos neste estudo estão sendo cruzados com outras informações produzidas sobre outros aspectos socioambientais da comunidade (economia, educação, saúde, manifestações culturais, conservação dos ecossistemas, entre outros). Esses resultados serão apresentados para a comunidade em reuniões, palestras, oficinas, etc... com objetivo de propor ações e construir soluções em um contexto mais complexo e representativo dos valores individuais e coletivos da comunidade.

\section{Agradecimentos}

Ao Programa de Educação Tutorial Conexões de Saberes Socioambientais, pela concessão da bolsa de estudos; à Comunidade Rural de Laranjeiras, por tornar possível o desenvolvimento deste projeto de pesquisa.

\section{Referências}

ALVES-MAZZOTI, A.J. Representações sociais: Aspectos teóricos e Aplicações à educação. Múltiplas Leituras, v. 1, n. 1, p. 18-43. 2008.

BARDIN, L. Análise de conteúdo. Lisboa, Personal, 1977. p. 31-41.

BRASIL. Ministério do Meio Ambiente. Identidades da educação ambiental brasileira. LAYRARGUES, P. P. (Coord.). Brasília, 2004.

COSTA, C.A.; LOUREIRO, C.F.B. Contribuições da pedagogia Crítica para a pesquisa em Educação ambiental: Um debate entre Saviani, Freire e Dussel. Revista Brasileira de Educação Ambiental. São Paulo, v. 10, n. 1, p. 180200. 2015.

IBGE - Instituto Brasileiro de Geografia e Estatística. Censo demográfico. 2010. Disponível em: http://www.censo2010.ibge.gov.br/. Acesso em: 25 out. 2013.

KELLERT, S.R. The biological basis for human values of nature. In: S.R. KELLERT e WILSON, E. O. (Eds.), The biophilia hypothesis. Washington, D.C.: Island Press, Shearwater Books, 1993. p. 42-69.

KRCMAROVÁ, J.E.O. Wilson concept of biophilia and the environmental movement and the USA. Klaudyán: Internet Journal of Historic Geography and Environmental History. n.1-2, p. 4-17. 2009.

LEE, J.; PARK, B.J.; TSUNETSUGU, Y.; OHIRA, T.; KAGAWA, T.; MIYAZAKI, $Y$. Effect of Forest bathing on physiological and psychological responses in Young Japanese male subjects. Public Health, v. 125, n. 2, p. 93-100. 2011.

OLIVEIRA, K.; CORONA, H.M.P. A percepção ambiental como ferramenta de propostas educativas e de políticas ambientais. ANAP Brasil. 1. 2008. p. 5372.

Revbea, São Paulo, V.10, N²: 25-35, 2015. 
PARK, B.J.; FURUYA, K.; KASETANI, T.; TAKAYAMA, N.; KAGAWA, T.; MIYAZAKI, Y. Relação entre as respostas psicológicas e físicas ambientes em ambientes florestais. Paisagem e Planejamento Urbano, v. 102, n. 1, p. 2432. 2011. doi: http://dx.doi.org/10.1016/j.landurbplan.2011.03.005

REVELL, G.; ANDA, M. Sustainable urban biofilia: The case of greenskins for urban density. Sustainability, v. 6, p. 5423-5438. 2014.

RYAN, C.O.; BROWNING, W.D.; CLANCY, A.; JOSEPH O.S.L.; KALLIANPURKAR, N.B. Biophilic design patterns: Emerging Nature-Based Parameters for Health and Well-Being in the Built Environment. International Journal of Architectural Research, v. 8, p. 62-76. 2014.

SANTOS, V. L.; MACHADO, L. M. C. P. Vínculos topo-biofílicos na relação visitantes e paisagens. In: GERARDI, L. H. O.; CARVALHO, P. F. (Org.). Geografia: ações e reflexões. Rio Claro: UNESP/IGCE: AGETEO, 2006. p. 311-326.

WILSON, E. O. Biophilia: The human bond with other species. Cambridge: Haward University Press, Cambridge, 1984, 157p.

WILSON, E. O. O futuro da vida: um estudo da biosfera para a proteção de todas as espécies, inclusive a humana. Rio de Janeiro: Campus, 2002, 242 p.

ZAGO, D. C. Animais da fauna silvestre mantidos como animais de estimação. 2009. 40f. Monografia (Especialização em Educação Ambiental) - Programa de Pós Graduação em Educação Ambiental, Universidade Federal de Santa Maria. Santa Maria. 